\title{
Dr. Michael Alexander Receives the First Molnar, Pediatric PM\&R Lifetime Achievement Award
}

JPRM is pleased to recognize Dr. Michael Alexander as the inaugural winner of the Gabriella Molnar, MD Pediatric Lifetime Award from the Foundation of PM\&R. Dr. Michael Alexander has dedicated his entire career to the pursuit improving this subspecialty of Pediatric PM\&R.

Dr. Alexander served as the Chief of Rehabilitation Medicine at the Alfred I. DuPont Hospital for Children in Wilmington, DE for over 26 years and has two decades of experience as a Professor at Thomas Jefferson Medical College. He was selected as Physician of the Year by the Pennsylvania Governor's Committee on Employment of the Handicapped in 1986 and received the American Academy of Physical Medicine and Rehabilitation's 2010 Distinguished Clinician Award. He is a Past President of the American Academy of Cerebral Palsy and Developmental Medicine and the Medical Society of Delaware.

Dr. Alexander received his Doctorate of Medicine from the University of Virginia School of Medicine and completed a combined residency of Pediatrics and Physical Medicine from Ohio State University and Children's Hospital in Columbus, Ohio. Started his academic career at Ohio State, then served at DT Watson Rehab Hospital for Children's in Pittsburgh for eight years and then spent the following 26 years at AI DuPont. He has held board certifications in Pediatrics, Physical Medicine and Rehabilitation, Electrodiagnostic-Subspecialty Board - Pediatric Rehabilitation Medicine.

During his career, Dr. Alexander has been responsible for training over two dozen pediatric rehab physicians. He is also the co-editor of the Pediatric Rehabilitation Principles and Practice textbook, now in preparation for its fifth edition.
Dr. Alexander feels the Pediatric Rehabilitation was the perfect field for him - "Pediatric Rehab medicine gave me the chance to work with children today, with my eye set on their future".

Dr. Alexander currently resides in Hockessin, Delaware. He has three children and two granddaughters whom he now watches two days a week in his retirement. Personally, his hobbies include Choral Singing for the past 12 years as a tenor in the New Ark Chorale and counts one of his performance highlights as appearing at St. Peters Cathedral in Rome. His group also performed the premiere of the Requiem for 9/11 by Wilson Somers, Nov. 2012 in Wilmington, De. He also enjoys aquatic container gardening.

Academically, he continues to be involved at AI DuPont and provides weekly resident lectures and maintains his academic appointment at Thomas Jefferson. Dr. Alexander is an Emeritus Medical Staff Member at AI Dupont.

Dr. Alexander will be providing the inaugural Gabriella Molnar lectureship at the 2014 AAPM\&R meeting in San Diego, his working title is "Societies' Treatment of the Disabled and Their Families Over the Centuries".

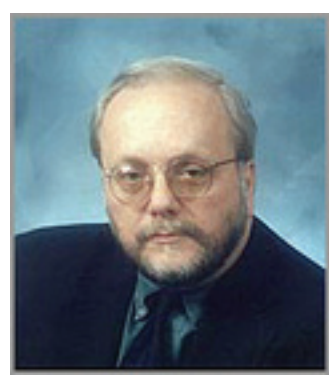

